\title{
Test research on the resistance performance of high-speed trimaran planing hull
}

\author{
Weijia Ma*, Ph.D., \\ Harbin Engineering University, China \\ Huawei Sun*, Ph.D., \\ AVIC Aerodynamics Research Institute, China \\ Jin Zou, Prof., \\ Heng Yang, Ph.D., \\ Harbin Engineering University, China
}

\section{ABSTRACT}

\begin{abstract}
In order to identify high-speed navigation ability of trimaran planing hull, as well as investigate the characteristics of its resistance and hull form, ship model tests were conducted to measure resistance, trim and heaving under different displacements and gravity centre locations. The test results were then used to study the influence of spray strips on resistance and sea-keeping qualities. Moreover, different planing surfaces were compared in the model tests which helped to look into influence of steps on hull resistance and its moving position. Also, the resistance features of monohull and trimaran planing hulls, both with and without steps, were compared to each other. From the tests it can be concluded that: the two auxiliary side hulls increase aerodynamic lift at high-speed motion, which improves the hydrodynamic performance; the trimaran planing hull has also excellent longitudinal stability and low wave-making action; when Fr $r_{\nabla}$ $>8$, its motion is still stable and two distinct resistance peaks and two changes of sailing state (the second change is smaller) appear; spray strips are favourable for sea-keeping qualities at high speed. The change trends before the second resistance peak as to the resistance and sailing behaviour of trimaran planing hull without steps are the same as for monohull planing hull without steps. but when steps in both hulls exist the change trends are different; more specifically: trimaran planing hull with steps has only one resistance peak and its resistance increases along with its speed increasing, and the resistance is improved at the increasing speed as the number of steps increases.
\end{abstract}

Key words: trimaran planing hull; side hulls; high speed; step; resistance; model test

\section{INTRODUCTION}

Trimaran planing hull has excellent navigation performance. It is constituted of a main ship hull and two auxiliary side hulls. The trimaran planing hull in combination of normal planing hull, high-speed multihull vessel and gas - layer - reducing - resistance ship, owns advantages of the three ship types. It has good hydrodynamical and aero-dynamical performance and operates in planing mode at normal stage of navigation. Due to its high speed and easy adjustment to different sea states trimaran planing hulls are applicable both to military and civil missions.

Currently, in some foreign countries design technology of trimaran planing hulls has been highly developed [1]. It not only has won frequently the championship in different boat races but also has been used as a unmanned weapon platform. Because of its high superiority, published technical papers are - for the sake of confidentiality- limited to real ship photos or introductory materials. Several Chinese researchers studied the design and performance of catamaran scooters by model and real ship tests [2-5]. Features of tri-wave-elimination planing boat were also analyzed [6]. At the same time, the operating principle, ship type character and general performance of channel-hydrofoil planing boat were explored [7-8]. And, experiments were also conducted on the hydrodynamic performance of high-speed craft [9]. Then resistance characteristics of channel-hydrofoil planing boat were studied [10]. In the paper [11] the effect of bottom steps on propulsion efficiency of high speed planing craft with outboard engine was analyzed. The operating principle and technology points of trimaran wave-absorption planing craft were then researched [12]. Effects of different locations of gravity centre, step patterns, air flow rates and air injection ways on resistance of stepped planing boat were studied comprehensively [13-18]. Further, its propulsion system was investigated by using a real craft [19]. A resistance regression formula for double stepped planing craft, based on data from the model tests [20], was elaborated. So far, there has been no Chinese paper related to trimaran planing crafts. Since resistance performance is significant for evaluating a new ship type, in this paper are discussed model resistance experiments carried out with the aim to check the high speed navigation ability of trimaran planing craft and its resistance performance with and without spray strips at different displacements and gravity centre locations. The model tests have been also used to explore the effect of steps on its resistance and voyage state. Finally, the test results and observed phenomena are combined in analyzing this ship type.

\footnotetext{
* These authors contributed to the work equally and should be regarded as co-first authors
} 


\section{TESTED MODEL AND ITS TESTING SCHEMES}

The moulded lines of the trimaran planing hull considered in this paper are shown in Fig. 1. Its features are as follows: the channels placed from bow to stern at both sides of the monohull planing hull, divide the hull into the main ship hull and two auxiliary side hulls. They make up two trumpet-like channels and form the hull cross sections similar to the shape of $\mathrm{M}$.

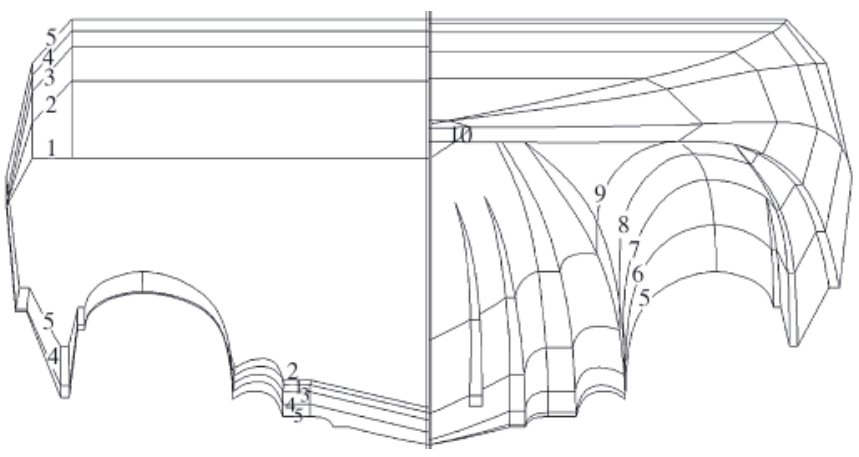

Fig. 1. Moulded lines of tested model

The ship model is made of FRP (fibreglass reinforced plastic) and its main hull is slender body whose length/width ratio is 7.32. The cross section of the auxiliary appendage is an inverse trapezoid with a bevel in both sides. Displacement of the auxiliary side hulls accounts for about $10 \%$ of the total displacement. The moulded lines and ship model are shown in Fig. 1 and Fig. 2, respectively. For comparison, the wooden spray strips are separately formed into two pairs of pyramidlike elements of the length/ship length ratio of 0.47 and 0.213 , respectively, and their pressurized-water angles are equal to $10^{\circ}$. The channel has a dome-roof with S-shape top body lines. The model has ten ordinates spaced by $240 \mathrm{~mm}$, and its stem is the tenth ordinate. The scheme of the model with three steps has the transverse steps (of $12 \mathrm{~mm}$ in height) set up at the ordinates: $2^{1 / 3}, 3 \frac{2}{3}, 5$, respectively. On the projection of ship bottom, the projection line of the steps at tail end is vertical to keel line, as shown in Fig. 3.

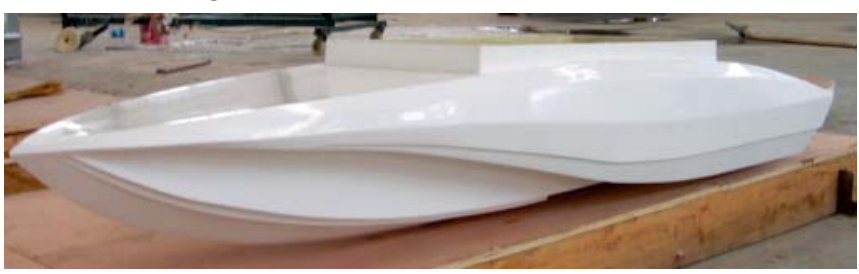

Fig. 2. The model of trimaran-planing boat

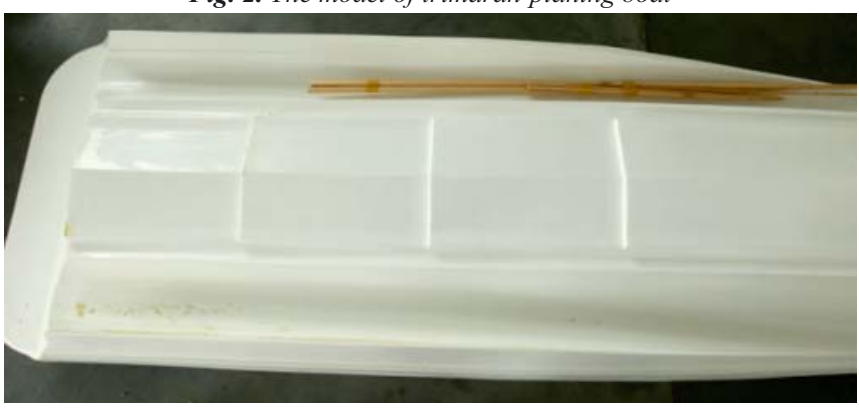

Fig. 3. Three transverse steps on the model body

The scheme of the model with two steps has the declined steps (of $6 \mathrm{~mm}$ in height) set up at the ordinates: $2 \frac{1}{3}, 3 \frac{2}{3}$, respectively. On the projection of ship bottom, the angle between projection line of the step at tail end and keel line is equal to $60^{\circ}$, as shown in Fig. 4.

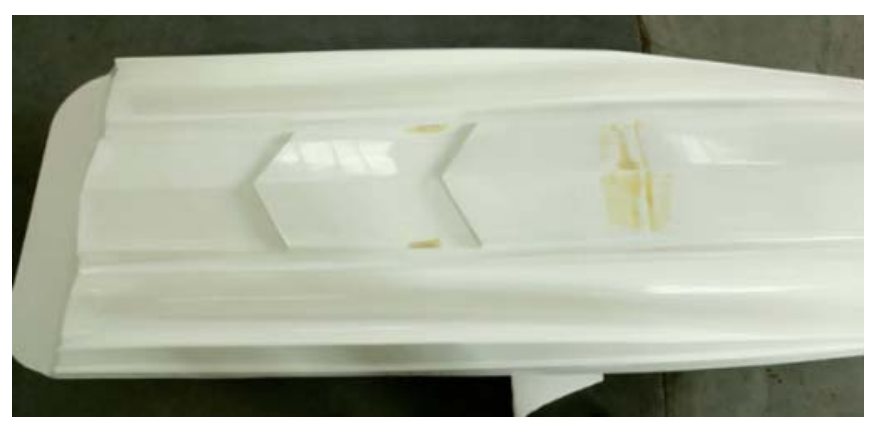

Fig. 4. Two declined steps on the model body

The scheme of the model with one step has the transverse step (of $6 \mathrm{~mm}$ in height) set up at the ordinate $32 / 3$, as shown in Fig. 5.

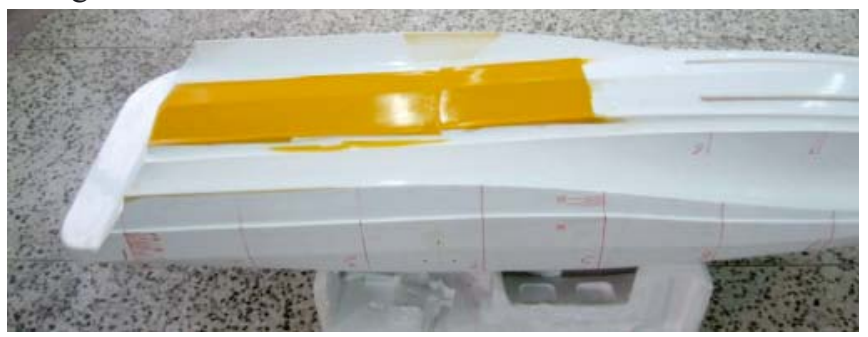

Fig. 5. One transverse step on the model body

The principal dimensions of the ship model are given in Tab.1.

Tab. 1. Principal dimensions of the ship model

\begin{tabular}{|c|c|}
\hline Principal dimension & Value \\
\hline Length L $(\mathrm{m})$ & 2.40 \\
\hline Moulded breadth B $(\mathrm{m})$ & 0.640 \\
\hline Bevel line breadth of main hull Bm $(\mathrm{m})$ & 0.297 \\
\hline Ordinate spacing $\Delta \mathrm{L}(\mathrm{mm})$ & 240 \\
\hline Average dead rise angle $\beta\left(^{\circ}\right)$ & 13 \\
\hline Scale ratio & $1: 6.46$ \\
\hline
\end{tabular}

One of the main characteristic features of the trimaran planing hull is its excellent rapidity. During the test, towing speed is brought to the limitation of the model tank before porpoising behaviour turns up. The resistance, trim and heaving in different states were examined by using four model tests in which the trimaran planing hull model was basically the same but the difference between them consisted in that one was without steps and the other ones with three different types of steps. The testing schemes are shown in Tab. 2.

\section{TEST RESULTS AND ANALYSES}

The model tests were carried out in the high-speed hydrodynamic tank of Aviation Industry Institute 605, Jingmen, China. The resistance, trim and heaving were tested by free towing method. In detail, the resistance was measured by means of an electrometric device with $0.2 \%$ accuracy; trim - by tilt sensor with $0.1^{\circ}$ accuracy and the up-pitch was taken positive; heaving was measured by a heave meter with $1 \%$ accuracy and rising was taken positive. The test results of the $\mathrm{drag} /$ lift ratio $\mathrm{R} / \Delta$, the trim $\alpha$ and the heave amplitude $\mathrm{H}$ against the change of the volumetric Froude number $\mathrm{Fr}_{\nabla}$ are shown in Fig. 6 through Fig. 8 . 
Tab. 2. Testing schemes

\begin{tabular}{|c|c|c|c|c|c|}
\hline No. of scheme & $\boldsymbol{\Delta}[\mathbf{k g}]$ & $\mathbf{I}[\mathbf{m}]$ & $\mathbf{d}[\mathbf{m}]$ & $\boldsymbol{\theta}\left[^{\circ} \mathbf{]}\right.$ & Remarks \\
\hline 1 & 40 & 0.62 & 0.144 & 3 & No spray strips \\
\hline 2 & 40 & 0.62 & 0.144 & 3 & Two pairs of spray strips \\
\hline 3 & 50 & 0.64 & 0.159 & 3 & Two pairs of spray strips \\
\hline 4 & 60 & 0.66 & 0.171 & 3 & Two pairs of spray strips \\
\hline 5 & 40 & 0.63 & 0.145 & 3 & No steps \\
\hline 6 & 40 & 0.63 & 0.145 & 3 & 3 transverse steps of $12 \mathrm{~mm}$ height \\
\hline 7 & 40 & 0.63 & 0.145 & 3 & 2 declinate steps of 6 mm height \\
\hline 8 & 40 & 0.63 & 0.145 & 3 & 1 transverse step of 6 mm height \\
\hline
\end{tabular}

where: $\Delta$ - stands for the weight of trimaran planing hull, 1 - represents the distance between centre of gravity and stern transom plate, $\mathrm{d}$ - shows designed draught, $\theta$ is trim when the ship model stands still

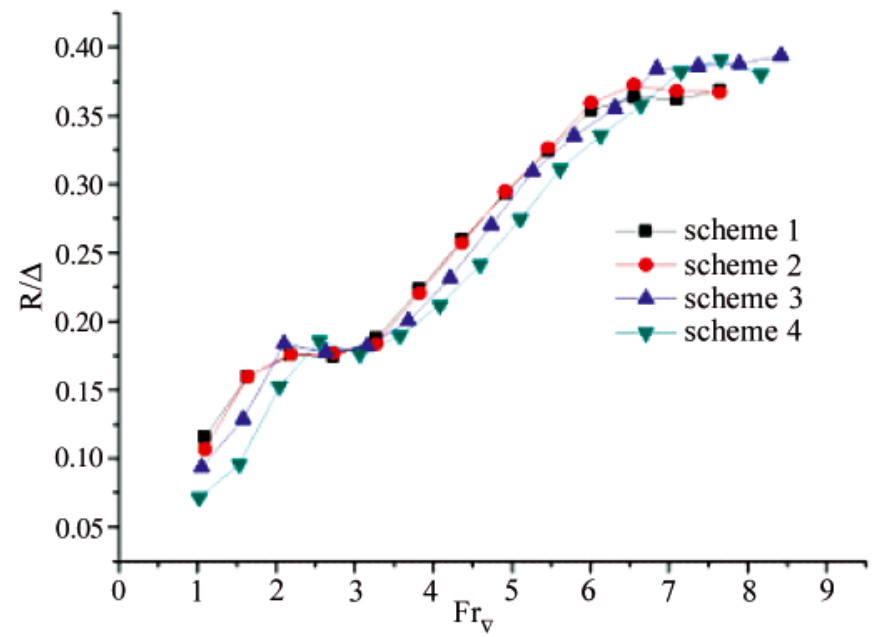

Fig. 6. Changes in drag/lift ratio for different testing schemes

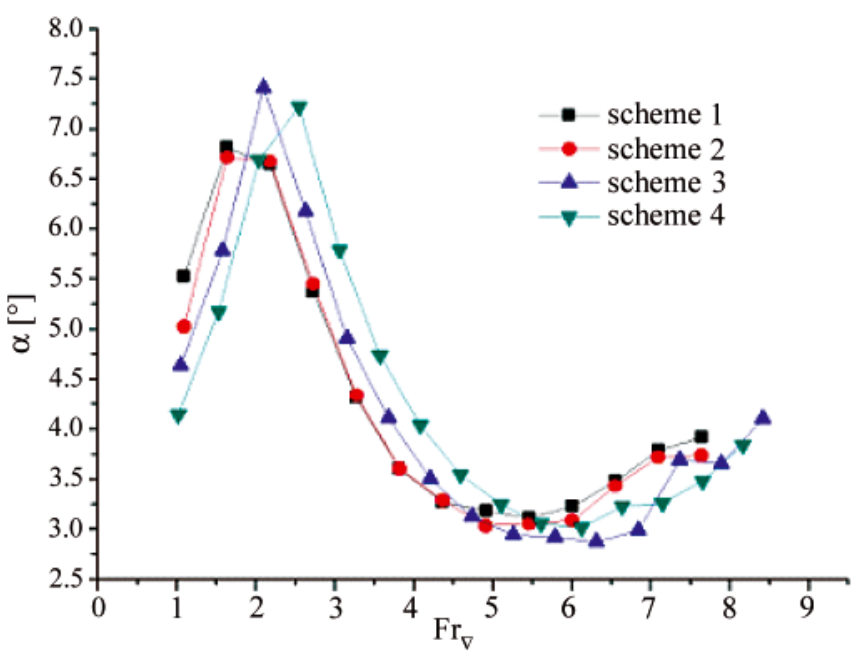

Fig. 7. Changes in trim for different testing schemes

The maximum towing speed allowable for the above mentioned tank is $16 \mathrm{~m} / \mathrm{s}$. In the testing scheme 1 and 2 when the towing speed reaches $15 \mathrm{~m} / \mathrm{s}\left(\mathrm{Fr}_{\nabla}=8.2\right)$, porpoising behaviour appears; while in the scheme 3 and 4 when the towing speed reaches $16 \mathrm{~m} / \mathrm{s}$ and the volumetric Froude number reaches 8.42 and 8.17 , respectively, the model behaviour is stable without porpoising motion. Generally, when the volumetric Froude number becomes greater than 5 , common planing crafts often show porpoising behaviour, while planing hulls with steps and catamaran planing crafts may also show porpoising behaviour at a low planning speed [20].

In several testing schemes the volumetric Froude number is greater than 8 , this shows that as for the longitudinal stability the trimaran planing hull performs better than the general monohull and catamaran planing crafts and has excellent capability of developing super-high speeds.

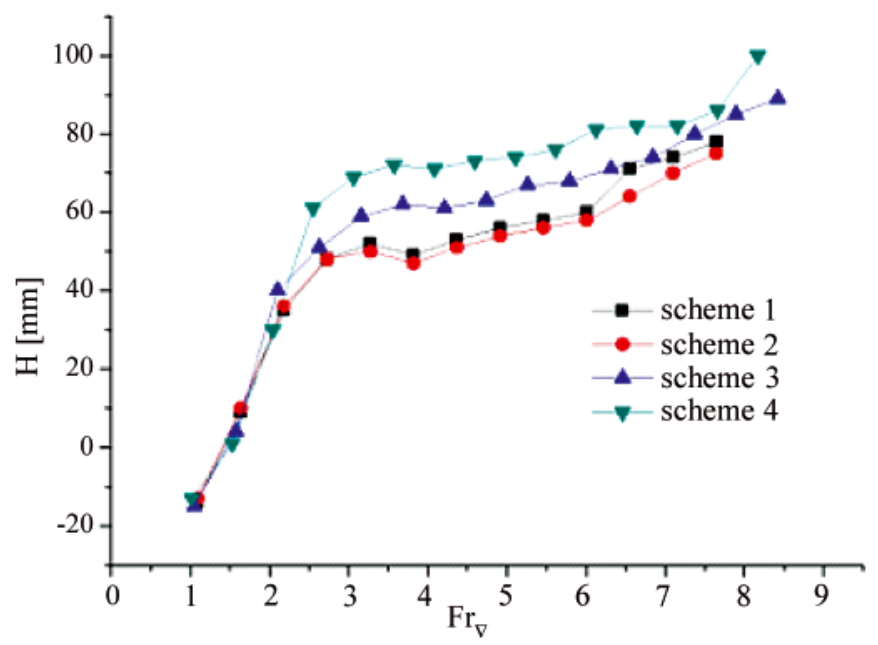

Fig. 8. Changes in heave amplitude for different testing schemes

As shown in Fig. 6, the resistance curve of the trimaran planing hull is similar to that of a seaplane in the first three phases of taking-off, as both of them have two drag humps [21]. But the drag humps of the trimaran planing hull are more distinct. The model speed when drag hump appears in different tests is shown in Tab. 3.

Tab. 3. Model speed when resistance crests appear

\begin{tabular}{|c|c|c|}
\hline & $\begin{array}{c}\mathbf{F r}_{\nabla} \text { at the first } \\
\text { resistance crest }\end{array}$ & $\begin{array}{c}\mathbf{F r}_{\nabla} \text { at the } \\
\text { second } \\
\text { resistance crest }\end{array}$ \\
\hline $\begin{array}{c}\text { Displacement: } 40 \mathrm{~kg}, \\
\text { no spray stripes }\end{array}$ & 2.15 & 6.6 \\
\hline $\begin{array}{c}\text { Displacement: } 40 \mathrm{~kg}, \\
\text { with spray stripes }\end{array}$ & 2.15 & 6.6 \\
\hline $\begin{array}{c}\text { Displacement: } 50 \mathrm{~kg}, \\
\text { with spray stripes }\end{array}$ & 2.2 & 7.1 \\
\hline $\begin{array}{c}\text { Displacement: } 60 \mathrm{~kg}, \\
\text { with spray stripes }\end{array}$ & 2.6 & 7.7 \\
\hline
\end{tabular}


It can be seen from Tab. 3 that as the displacement increases and the gravity centre moves forward, the drag hump moves backwards and the volumetric Froude number needed to cross drag hump Increased, the drag hump increases continually. And, the fact whether the spray strips are installed or not has a little effect on the resistance and ship behaviour until the second drag hump appears when the resistance of model with spray strips increases by $2.5 \%$. But the spray strips have no effect on the position of drag hump.

As shown in Fig. 7, the trim of the trimaran planing hull, unlike the monohull planing crafts [22], has two peaks and the second peak is distinctly lower than the first one in navigation. As shown in Fig. 8, the trimaran planing craft is greatly uplifted two times; the first uplifting happens before getting into planning and the second happens when crossing the second drag hump; but the value of the second uplifting is smaller than the first one. The spray strips has no effect on trim and heaving before planning. But they become smaller after planning in the case of application of spray stripes when the curves are comparatively flat. It will greatly improve navigation ability of the high-speed trimaran planing hull as the aerodynamic lift cannot be ignored when the volumetric Froude number is greater than 6 .

The following phenomena were observed in the tests: the channels at both sides are immersed in water when the ship model stands still; the wetted breadth of the channel and auxiliary side hulls decreases with the increasing of model speed when the model is in hull-borne and semi-planing stage $\left(0<\mathrm{Fr}_{\nabla} \leq 3.0\right)$; the channel are fully ventilated with its top above water surface when the model starts to plane $\left(\mathrm{Fr}_{\nabla} \approx 3.0\right)$. Apart from the wave induced by ship motion, there appears transverse flow forming spray in the channels due to pressure difference between planing surface and ambient pressure. As shown in Fig. 9, both sides demonstrate distinct wave-making and a little spray, which then forms "chicken wake" behind the stern. With the increase of speed the wave-making declines while the spray - forming increases, and the distance between the "chicken wake" and the stern rises gradually.

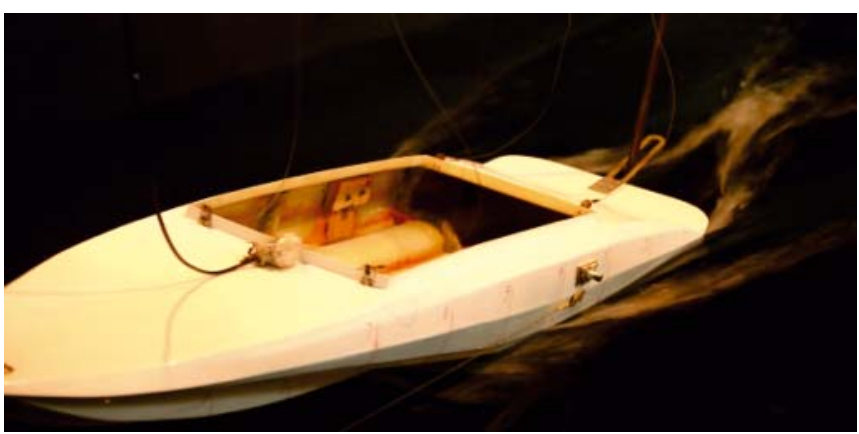

Fig. 9. Phenomena during the test at $F r_{\nabla}=2.2$

As shown in Fig. 10, in the planing stage $\left(3.0<\mathrm{Fr}_{\nabla}<6.0\right)$ the splashing rises further, while the "chicken wake" decreases gradually and the wake furls to the middle part. In this stage the resistance is approximately proportional to $\mathrm{Fr}_{\nabla}$. The channels are filled with air-water mixture and the wetted breadth of the auxiliary side hulls decreases with the increasing of model speed.

As shown in Fig. 11 the model is in the high-speed planing stage $\left(\mathrm{Fr}_{\nabla}>6.0\right)$. With the increase of speed the model hull uplifts and the auxiliary side hulls get out of the water gradually till only the after body touches the water surface. The wavemaking and splashing caused by the main hull are absorbed and obstructed by the auxiliary side hulls. Air layer, air-water mixture layer and splashing layer are formed from top to bottom in the channels. The water escapes in the form of spray column at the stern and the wake is relatively flat.

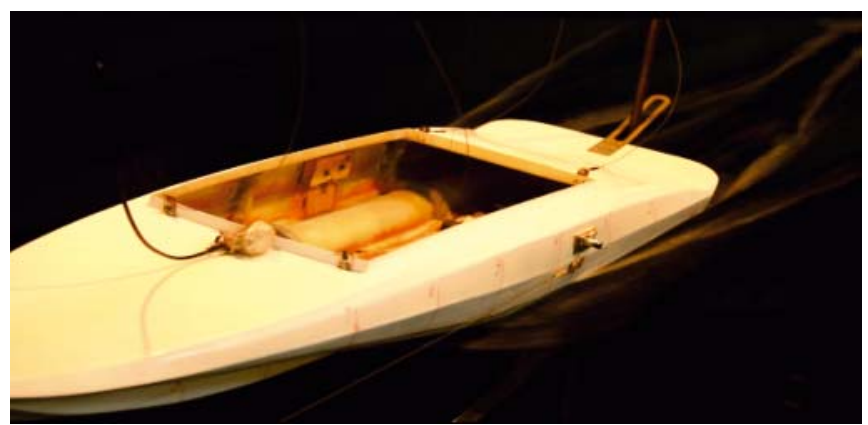

Fig. 10. Phenomena during the test at $F r_{\nabla}=3.8$

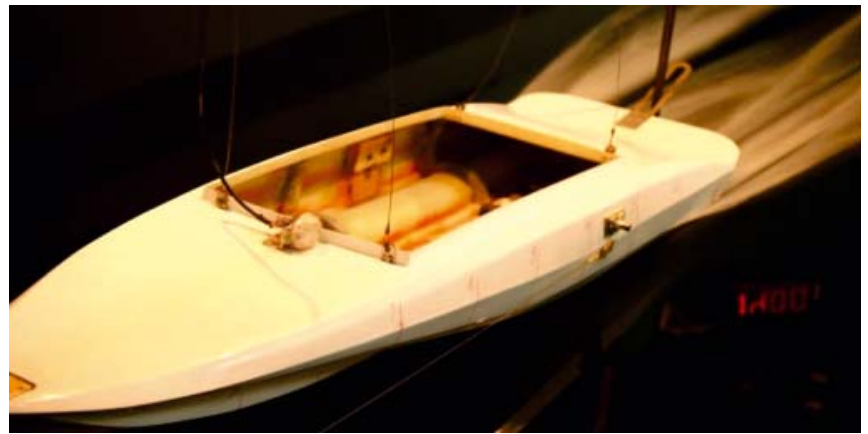

Fig. 11. Phenomena during the test at $F r_{\nabla}=7.6$

It can be seen from the above decribed tests that: the main hull offers most of the effective buoyancy when the model is in still-stand and hull-borne mode; when the model is in highspeed mode, i.e. the main hydrodynamic planing surface is formed, the main hull produces most of the hydrodynamic lift. In the high-speed mode the hull is supported by hydrodynamic and aerodynamic lift, so the main hull will have enough dynamic lift even if it is narrow. The main effect of the channels at both sides consists in producing the aerodynamic lift at high velocity, which supports the hull and improves its seaworthiness. When the ship model is still standing or at a low speed the auxiliary side hulls are all immersed in water giving extra static buoyancy; and, at high speed they obstruct wave-making and splashing.

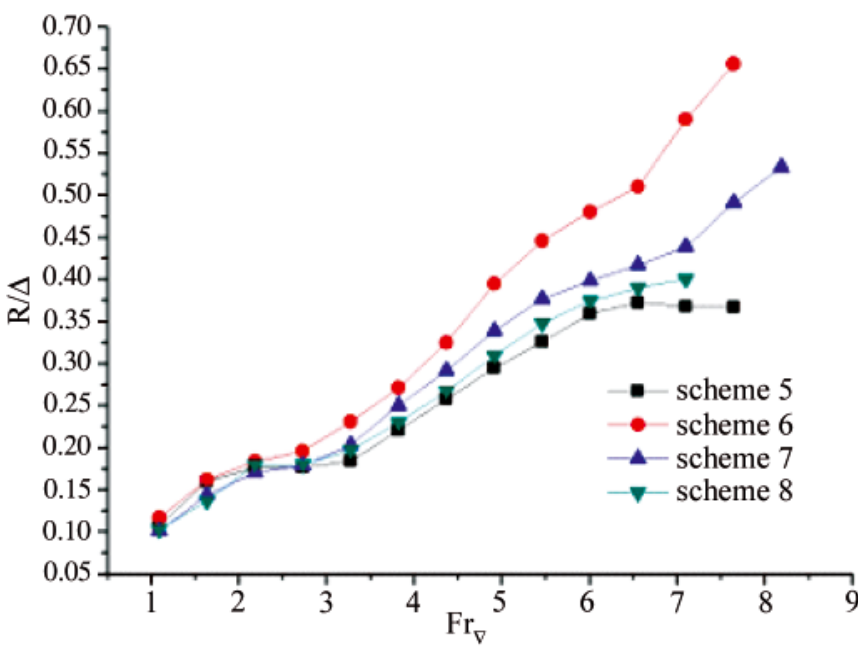

Fig. 12. Effect of steps on the drag/lift ratio

The drag/lift ratios $\mathrm{R} / \Delta$ ( where $\mathrm{R}$ and $\Delta$ stands for the total resistance and the model weight, respectively) versus the volumetric Froude number are shown in Fig. 12. When $\mathrm{Fr}_{\nabla}<2.18$ the change trend of the drag/lift ratio for the model 
with three transverse steps is in compliance with that for the model without steps; the resistance of the model with three steps is a little bigger, and the resistance of the model with one or two steps is somewhat smaller, compared with that for the model without steps. When $\mathrm{Fr}_{\nabla}>2.18$ the resistance of all models with steps is bigger than that of those without steps, especially the resistance of the model with three steps, which is by $78.78 \%$ larger when $\mathrm{Fr}_{\nabla}=7.65$. The resistance of the model without steps decreases when $\mathrm{Fr}_{\nabla}>6.55$, and the resistance of that with two steps increases sharply; and, the resistance of the model with one step also increases and its porpoising behaviour appears when $\mathrm{Fr}_{\nabla}=7.65$.

General monohull planing crafts in motion have only one drag hump, and after crossing the drag hump the resistance increases monotonically. Trimaran planing hulls without steps have two distinct drag humps between which the resistance increases monotonically, and after crossing the second drag hump the resistance tends to drop.

When the monohull planing craft enters planing state the resistance changes a little with the increasing of speed in a certain range. The planning efficiency rises and the resistance decreases with increasing number of steps. The resistance curve of trimaran planing hull with steps has only one drag hump. When it enters planing state the resistance increases distinctly. The more the steps the greater the resistance in high speed.

In Fig. 13 is shown the curve of trim against different values of the volumetric Froude number. In the process of towing two peaks can be observed for the none-step scheme in which the trim is larger than that in three-step scheme and in two-step scheme. The second peak appeared in the following order of the schemes: that of three-steps, two-steps and none-step. Particularly, porpoising behaviour turns out for one-step scheme at $\mathrm{Fr}_{\nabla}=7.65$, which results in only one peak; and the trim, if compared to that for none-step scheme, is smaller at $\mathrm{Fr}_{\nabla}<2.18$ and $\mathrm{Fr}_{\nabla}>3.82$ but almost the same at $2.18<\mathrm{Fr}_{\nabla}<3.82$.

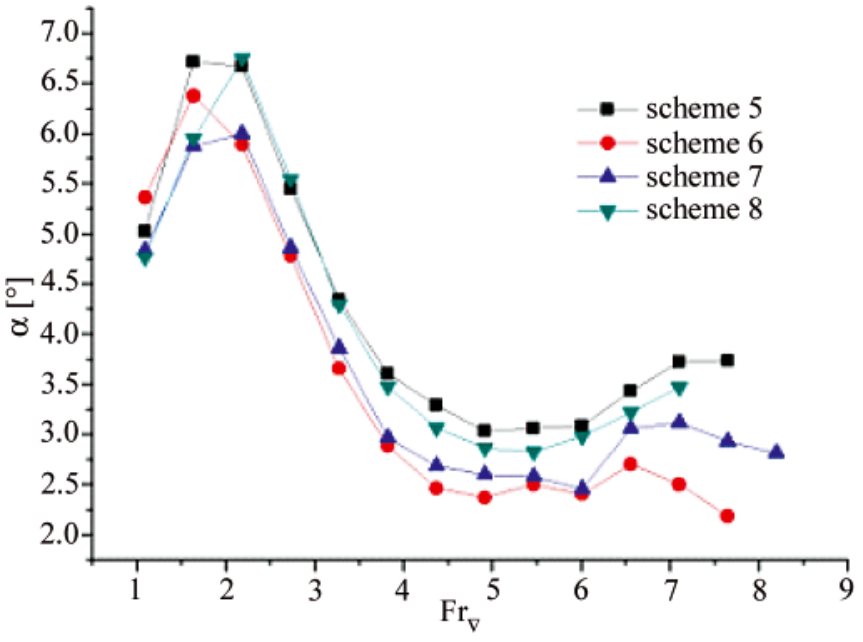

Fig. 13. Effect of number of steps on trim

Fig. 14 shows the heaving $\mathrm{H}$ against different values of the volumetric Froude number for four schemes. The heaving for three-step scheme is smaller than that for none-step scheme and, the first crest and trough are not distinct. As to the twostep scheme, its heaving curve is partly different from that of none-step scheme; their change trends at $\mathrm{Fr}_{\nabla}<3.28$ are the same and the heaving values differ a little; their first peaks are at $\mathrm{Fr}_{\nabla}=3.82$ and $\mathrm{Fr}_{\nabla}=3.28$, respectively, and their second peaks are at $\mathrm{Fr}_{\nabla}=5.46$ and $\mathrm{Fr}_{\nabla}=6$, respectively. The heaving curve for one-step scheme is in accordance with that for none-step scheme whose heaving value is a little bigger.

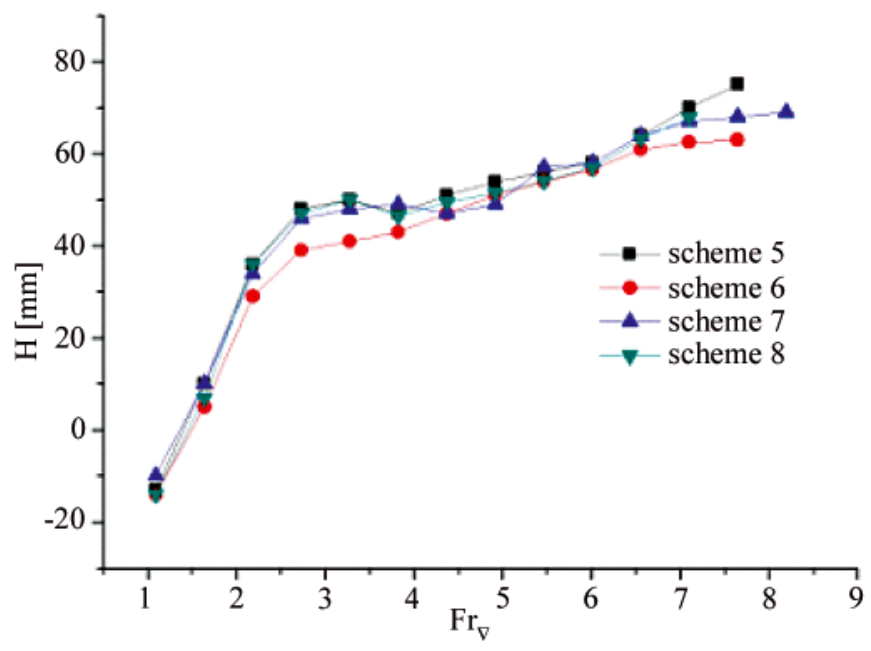

Fig. 14. Effect of number of steps on heaving

In hull-borne and semi-planing state, as the velocity grows, the trim of general monohull planing craft increases distinctly and the hull uplifts rapidly. After entering planing state, its trim decreases gradually and the hull uplifts slowly.

As the two curves indicate, the voyage states of trimaran planing crafts without steps could be divided into three stages: in the first stage, when the vessel is in hull-borne and semiplaning mode, its trim rises fast and the hull uplifts dramatically. The second stage comes after entering planing, when the trim decreases steadily and the uplifting amplitude also decreases. The third stage occurs before crossing the second resistance crest, when the trim rises again and the uplifting amplitude increases, but the trim and heaving are smaller than in the first stage.

The voyage states of monohull planing hull with steps can be also divided in three stages over the whole speed range. The first stage ends before the drag hump, when the trim and heaving increases gradually with the rise of speed. The second stage comes after the drag hump in planing state, when the trim sustains nearly unchanged and the hull uplifts steadily. In the third stage $\left(\mathrm{Fr}_{\nabla}>7.5\right)$, the hull uplifts further and the trim falls a little, when the full-breadth planing becomes partbreadth planing in which the kinetic stability may be lost. The only difference between trimaran planing hull with steps and that without steps is that the velocity is different when trim and heaving changes. Except the one-step scheme where porpoising behaviour appears at $\mathrm{Fr}_{\nabla}=7.65$, the other two schemes are excellent as to motion stability of the crafts.

During the tests the spray is observed at the sides of the trimaran planing hull. Generally, regardless of whether monohull planing crafts have steps or not, strong spray will occur at high speed. As to none-step trimaran planing crafts, with the rise of speed at $\mathrm{Fr}_{\nabla}>6$, the auxiliary side hulls take slowly off the water surface and the wave-making and splashing caused by the main hull are absorbed and obstructed by them, as seen in Fig. 15; and, air-cushion layer is formed in the top of the channels and the flow of air-water mixture is totally free. As to other schemes with steps, the spray splashes out of the border, which leads to vortex and turbulence. Therefore, the none-step scheme has a much smaller wet area than other schemes, thereby has a smaller frictional resistance, which could be one of the reason why the resistance of none-step scheme is lower than that for other schemes. 

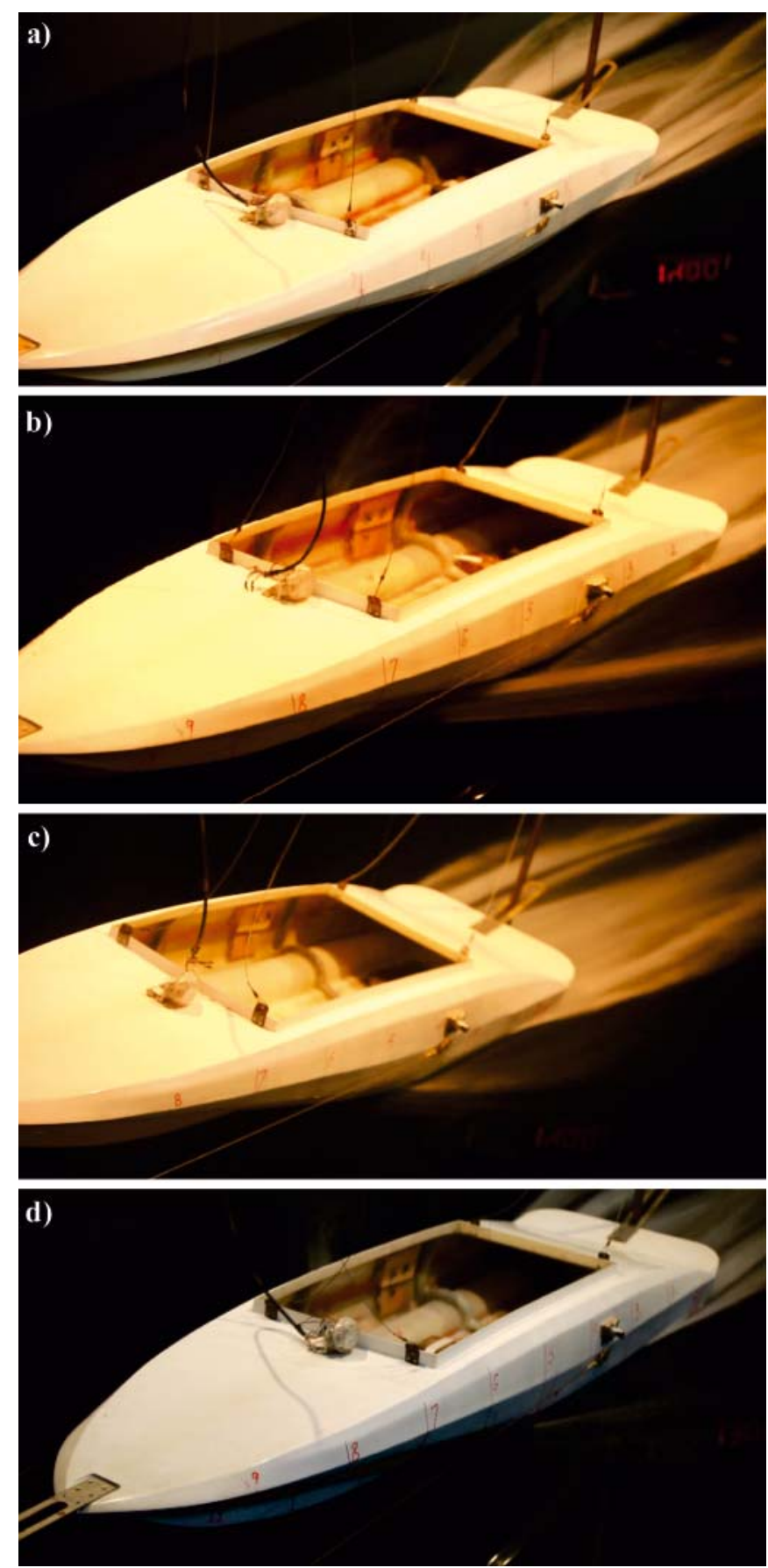

Fig. 15. Spray forming at the sides for different model schemes. a) none-step model, $F r_{\nabla}=7.6$; b) three-step model, $F r_{\nabla}=7.6$; c) two-step model, $\mathrm{Fr}_{\nabla}=7.6$; d) one-step model, $\mathrm{Fr}_{\nabla}=7.1$

\section{CONCLUSIONS}

This article mainly discusses the resistance performance of trimaran planing vessels. The resistance tests took into consideration several factors, including steps (applied or not), step patterns, and types of planing surface. Also, water splash beside the hulls under high speed was observed.

On the basis of the obtained test results the following conclusions can be offered:

1) The trimaran planing crafts have good longitudinal stability and high-speed navigation ability.

2) Influenced by aerodynamic lift, the trimaran planing hull has two distinct resistance crests. At high speed it sustains stable and its pitch and heave are small.
3) In the performed tests the influence of spray strips on the trimaran planing hull resistance performance appeared not distinct, but it can improve its navigation ability when the vessel enters planing.

4) Static buoyancy and dynamic lift supporting trimaran planing hulls are mainly provided by the main hull. The added auxiliary side hulls on one hand constitute together with the main hull - the flow channel to generate aerodynamic lift; on the other hand they obstruct wavemaking and splashing at high speed.

5) Trimaran planing hull without steps has two distinct resistance crests within the navigation range and the resistance between the two resistance peaks increases almost linearly. The pitch angle curve has also two peaks and the change of amplitude of the second peak is smaller than that of the first one; The heaving values, relative to pitch angle changes, increased greatly two times within the testing range. When steps are added to the hull, its resistance becomes larger, the second resistance hump disappears, the resistance increases with the increasing number of steps, the pitch angle and heaving displacement are both smaller than for the scheme without steps and the change trend of their curves is basically identical; and, the second peak of pitch angle and the second large rise of heaving appear earlier with the increasing number of steps.

6) The change trends before the second resistance crest of resistance and sailing behaviour of trimaran planing hull without steps are the same as for monohull planing hull without steps.

7) The greater number of steps of the craft, the larger its resistance. Installing the steps does not cause porpoising behaviour to emerge earlier, and, the longitudinal stability of the craft maintains excellent.

8) The trimaran planing crafts without steps, opposite to monohull planing hulls ( both with and without steps) and trimaran planing crafts with steps, keep the splash within the channel, thus make it low, and form an air cushion layer which reduces the resistance.

\section{BIBLIOGRAPHY}

1. Lorne Frederick Campbell: Entrapment Tunnel Monohull Optimized Waterjet and High Payload. 7418915B2, 2007.9.20, USA.

2. Liu Qian, Hou Yutang, Wang Zhentao, et al.: Development of high-speed twin-hulled planing boat. Ship Engineering, 2,1999.

3. Liu Qian, Hou Yutang, Zhao Hua, et al: Design and experimental research of catamaran planing boat on plateau water. Shipbuilding of China, 3, 1999.

4. Liu Qian, Hou Yutang, YU Wudi, et al.: Effects of principal dimensions, moulded lines and parameters of channel on speed and powering of catamaran planing boat. Shipbuilding of China, 3, 1998

5. LIU Qian, Wang Zhentao: The distinguishing features, uses and development trends of high-speed planing catamaran. Jiangshu Ship, 15(1), 1998.

6. Liu Qian, Pang Liguo, Lei Yunhong: Research on working principle and technical features of tri-wave-elimination planing boat. Jiangshu Ship, 17(1),2000

7. Su Yongehang, Zhao Lianen: A study on characters of high performance channel type planing boat. Shipbuilding of China, $1,1996$.

8. Zhao Lianen, Li Jide, He Yi: A study on performance of channel-hydrofoil-type planing boat. Shipbuilding of China, 3 , 1997.

9. CHI Yunpeng, Meng Xianqin: Experimental investigation on resistance an seakeeping performance for high speed channel crafts. Ship Engineering, 3. 1995. 
10.Zhao Zhiping: Characteristics of resistance for channel type planing boat. Journal of Dalian Fisheries University, 12(4),1997.

11..Huang Zhengang:The effect of bottom steps to the propulsion efficiency of high speed planing craft with outboard engine. Ship, (3), 1996.

12.Liu Qian, Pang Liguo: The operating principle and technology points of trimaran wave-absorption planing craft. Jiangsu Ship, 17(1), 2000

13.Dong Wencai, Guo Rixiu: Effects of Different Air Injection Techniques on Resistance of Stepped Planing Boat. Shipbuilding of China, 41(2), 2000.

14.Dong Wencai,Guo Rixiu: Air injection on the bottom of stepped planing craft and its effect on resistance. Journal of Ship Mechanics, 4(3), 2000.

15.Dong Wencai, Guo Rixiu: Study on the mechanism of resistance reduction to the stepped planing craft by air injection. Journal of Ship Mechanics, 6(6), 2002.

16.Dong Wencai, Guo Rixiu: Experimental study on resistance reduction of planing craft by air injection. Shipbuilding of China, 43(4), 2002.

17.Dong Wencai, Guo Rixiu: Experimental investigation on the resistance reduction of stepped planing craft by formation of air cavity. Journal of Hydrodynamics, 17(4), 2002.

18.Xia Xiang: Matching performance of propulsion system for hyper-velocity step planing boat. Chinese Journal of Ship Research, 3(2), 2008.
19.Shen Xiaohong, Wu Qirui: A resistance regression formula for double stepped planing craft. Chinese Journal of Ship Research, $5(2), 2010$.

20.Zhao Lianen,Han Duanfeng: Hydrodynamic principle and design of high-performance ships. Harbin Engineering University Press, Harbin, 2000.

21.Troop 916 of People's Liberation Army: Fluid mechanics of seaplane. Translated by COMFORAER, 1963.

22. Yue Guoqiang, Yao Chaobang, Dong Wencai: Study of influence factors on resistance of deep-V planing craft in still water. Chinese Journal of Ship Research, 4(3), 2009.

\section{CONTACT WITH THE AUTHORS}

Weijia Ma, Ph. D.

College of shipbuilding Engineering, Harbin Engineering University, Nan tong street Harbin, HLJ, P. R. CHINA, e-mail: maweijia@live.cn

Huawei Sun, Ph. D.

AVIC Aerodynamics Research Institute, China, Nan tong street Harbin, HLJ, P. R. CHINA, e-mail: sunhuawei0051@163.com 